\title{
An Approach of Simple Linear Sequential Techniques for Examination Venues Placement in UiTM Pulau Pinang Branch
}

\author{
Jamal Othman ${ }^{1 *}$, Naemah Abdul Wahab ${ }^{2}$, Rozita Kadar ${ }^{3}$, Hanisah Haszirah Mokhtar ${ }^{4}$ \\ ${ }^{1,2,3}$ Department of Computer and Mathematical Sciences, \\ Universiti Teknologi MARA Cawangan Pulau Pinang, Malaysia \\ ${ }^{4}$ Department of Computer and Mathematical Sciences, \\ Universiti Teknologi MARA Cawangan Perlis, Malaysia

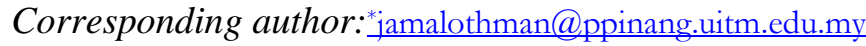 \\ Received Date: 21 May 2019 \\ Accepted Date: 19 September 2019
}

\begin{abstract}
Amongst the important module of Examination Management Systems (EMS) is the process of examination venues placement for the courses and students. At UniversitiTeknologi MARA(UiTM) Pulau Pinang Branch (PermatangPauh Campus), this task will be started whenever the timetable of the courses has been announced on the student portal website. The manual method of assigning the venues for each course using Microsoft Excel leads to some major problems such as the unconsciousness of excessive student load in an examination hall and the examination of the same course code was distributedat separate examination halls. Simple Linear Sequential Approach has been introduced to solve the problems and improve the examination management process. The Simple Linear Sequential Approach has been modified by embedding additional variables such as determination of total students by each session of examination and separation of different duration of examination at the same venue of examination. This approach improves and produce better placement of examination venues for the courses and students.
\end{abstract}

Keyword: EMS, Linear Sequential, Examination Placement, SDLC, SIMs

\section{INTRODUCTION}

Examination procedure is the most crucial tasks at the Department of Academic Affairs. Besides records and administration functions, the examination becomes the key function which involves the preparation of question paper, printing and packaging of question paper, handling of examination operations and students' marks management (Quality, 2010) and (UiTM, 2016).

Handling of examination operations itself involves several submodules such as the preparation of examination timetable of the courses, examination placement process and invigilation (Othman. J, et. all, 2017). This paper mainly will be focusing on the preparation of assigning the subjects or courses with final examination at the appropriate location in proportion to the capacity of the room. Currently, the Examination Unit of UniversitiTeknologi MARA Pulau Pinang Branch (PermatangPauh Campus) used the Microsoft Excel and manually allocating the halls or examination locations for each course. Nevertheless, unpredicted issues or problems have arisen such as students accidentally overloaded at the examination halls that lead to question papers are insufficient to be distributed to the students during the incidence. 
The time required to produce the class timetable is depending on the total number of students and diversity of the courses offering to the faculties or departments (Bloomfield and McSharry, 1997). UiTM campus has thousands of students who need an automated scheduling system to improve the effectiveness and the quality of examination venue arrangement for students. The process of arranging the examination venue is quite complex and time consuming because it involves huge volumesof data as well as varieties of hard and soft constraints.

In the situation of UniversitiTeknologi MARA Pulau Pinang Branch (PermatangPauh Campus), the examination unit staffs have requested that the courses to be placed in one room or examination halls to be determined during the examination placement process. This request correlated to avoid errors during packaging of question papers. Another request is the number of courses allocated in examination halls should not exceed five courses per examination slot. This demand is related to the easiness of handling the examination operations by the invigilators.

Therefore, to improve the process of examination venues placement or venues arrangement, an algorithm has been developed, tested and proposed to automate the process. Techniques or algorithms of examination venues placement has been studied, evaluated and customized into according to the situation of UniversitiTeknologi MARA Pulau Pinang Branch (PermatangPauh Campus).

The paper is organized as follows. The next section explores on the related work on management of examinations at present. The followed section discusses on the proposed work that could contribute to the effectiveness of the examination management. Finally, we conclude the paper and proposed the future work.

\section{RELATED WORK}

Timetabling is a special type of scheduling (Wren A., 1996). Wren defined timetabling as a process of allocation, which subject to set of constraints, of a given resources to be placed in a specified time, in such a way to satisfy as nearly as possible to the desirable objectives. Both examination data and constraints are correlated to each other to produce the most optimize results of examination schedules which satisfy the desired main requirements.

The examination and class timetable have entirely different constraints and considerations (Bloomfield and McSharry, 1997). Timetabling involves big volume of data and constraints such as number of students, courses, programs, timeslots and rooms capacity that able to accommodate certain number of students. Timetabling constraints are many and varied such as resource assignment, time assignment, time constraints between meetings, spread and coherence of meetings, room capacities and continuity.

Preparation of examination timetabling in UK Universitiesare also facingsimilar problems in developing the examination schedule. They agreed that the biggest problem for universities is finding the space to allocate the exams. (Burke et al, 2001). According to the journal proceeding of University Examination Timetabling, the constraints are translated by using mathematical formulation as integer programming. In comparison, other journal use evolutionary algorithm and heuristic approach to solve these constraints. 
Works that are related to the preparation of assigning venues for university examination has been identified. The timetabling system called August is developed by the Automated Scheduling and Planning Group at University of Nottingham, UK (Burke et al, 2001). Theproject started in July 1994 and released in July 1997 for UK Universities. It took 3 years to complete the project. This system incorporates an evolutionary algorithm developed at Nottingham, and a highly flexible method of specifying resources and constraints information, making it applicable to a wide range of academic timetabling problems. Researcher described the resources such as rooms that have relevant and appropriate attributes then possess it with certain attribute values as shown in the Table 1 below.

Table 1: Attributes value

\begin{tabular}{|l|l|}
\hline Attribute Name & \multicolumn{1}{c|}{ Attribute Values } \\
\hline Wheelchair access & True if the room is accessible by wheelchair \\
\hline Purposes & $\begin{array}{l}\text { The uses of the room may be put to } \\
\text { e.g.: lecture theatre, computer lab, etc. }\end{array}$ \\
\hline Building & $\begin{array}{l}\text { The building in which the room is situated } \\
\text { Capacity }\end{array}$ \\
$\begin{array}{l}\text { The number of students which the room can } \\
\text { accommodate }\end{array}$ \\
\hline
\end{tabular}

The second approach is the heuristic approaches in solving the timetabling problems. Amongst the techniques that are commonly used are the hill climbing, meta-heuristic method, constraint-based and fuzzy-based method as mentioned by (Chand, 2002) and (Abdullah, 2006).The third interesting approach is the Bin Packing Algorithm. Bin Packing is a mathematical way to deal with efficiently fitting Elements into Bins (Benko and Gyorgy, 2014). The goal of every Bin Packing algorithm is to use the least amount of Bins to hold the required number of elements. Given the size of item is $p_{x}$ where $x$ is $1 \ldots n$. These items need be packed into minimal number of bins. The size of items inserted cannot be more than the capacity of the bin. The bin will be covered if the size of item packed into the bin.

\section{PROPOSED WORK}

This section discusses the methodology of the proposed work that involved forthe development of automated venue placement and further clarifies the software, hardware and technique required for this project. Suitable algorithm is designed, customized and achieved the requirement as stated by examination placement policies.

The following Figure 1 below shows the proposed research methodology framework with six phases which are; planning, analysis, design, coding or implementation, testing and finally the maintenance. This framework is adapted from the Waterfall Model of System Development Life Cycle (SDLC) (Kenneth and Julie, 2014).

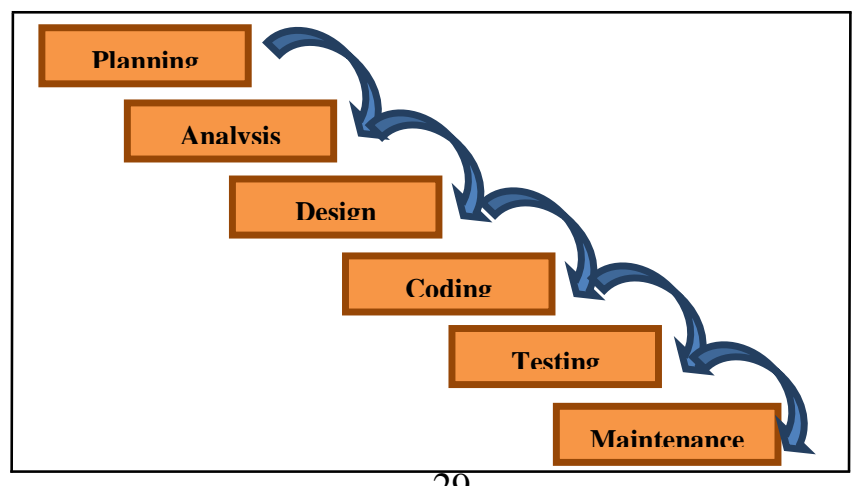


The planning phase is important as a guideline to perform preliminary investigation to identify the nature and scope of this project.The analysis phase is focused on analysing the concepts and approaches used in order to develop the automated placement of venue for examination scheduling system project.The next phase is the design, whereby, activities involved are designing the algorithm and content ideas by reviewing the pseudo-code to generate the examination venue placement.

The implementation is the activity of transforming the system design or algorithm into coding. While coding is written, the testing activities can be executed in parallel.The algorithmis tested frequently to ensure the rooms could be assigned properly without violating the number of students exceeded the examination hall capacity. Finally, the maintenance is the activity of improvising the system to sustain the users' acceptance, meet the goals of the project and fulfils the ad hoc requirements raised by the users.

Sample data of students' enrolment as well as list of examination rooms and halls have been identified and analyse. The critical part of this project is by designing the algorithm to occupy and optimize the examination rooms without overloaded problems. The algorithm should consider the following basic guidelines or requirements as stated by the Examination Unit as shown in Table 2 below.

Table 2: The System Requirements

Hard Constraints

Each subject code enrolled by the student is assigned with the examination venue.

Each examination venue has no overloaded issues. E.g.: the room capacity is 100 , but the total number of students assigned to the rooms is 120 , thus, overloading of 20 students. This situation considered a failure.

\section{Soft Constraints}

Every subject code is assigned in one examination venue only. Exception given if the numbers of enrolments are larger than the venue capacity.

The subject codes with longer duration of examination are placed in front of the examination venue. E.g.: The three hours examination will always be seated in the front row of the examination room, while the two hours examination duration is at the subsequent row.

The requirements of the systems are categorized by hard and soft constraints to stress that which requirements are important or optional respectively (Hicks, Medland and Mullineux, 2006). Hard constraints means, the requirement is important and must be prioritized, while the soft constraint is optional or less priority to be considered during the process of examination venue placement. Hard constraints are normally correlate with the project objectives.

The data of students' enrolments have been downloaded from the SIMS (Student Integrated Management System). The records are analysed before being integrated with the records of examination scheduled. After the integration of enrolments and examination records, the next step is the process of assigning the examination venue by using the technique called Simple Linear Sequential approach. The real data of December 2018 Final Examination has been used to examine the effectiveness of the algorithm. The following Figure 2 shows the proposed EMS Model framework design following the six stages. 


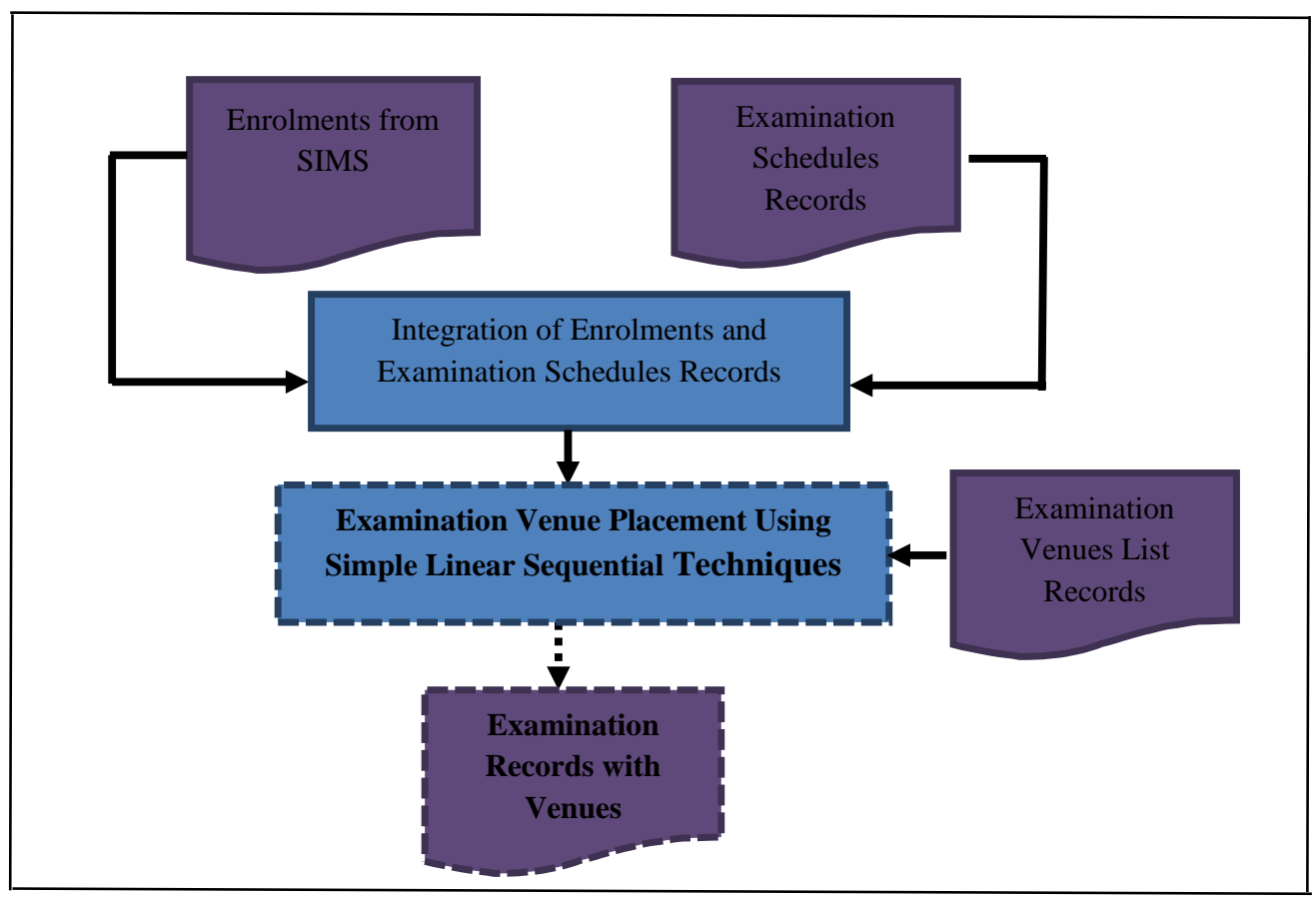

Figure 2: The detailed overview of the proposed EMS model framework design.

The following figures are the sample of enrolment (Figure 3), examination schedules (Figure 4) and the examination venues list records (Figure 5) which has been extracted from the SIMS (Student Integrated Management Systems).

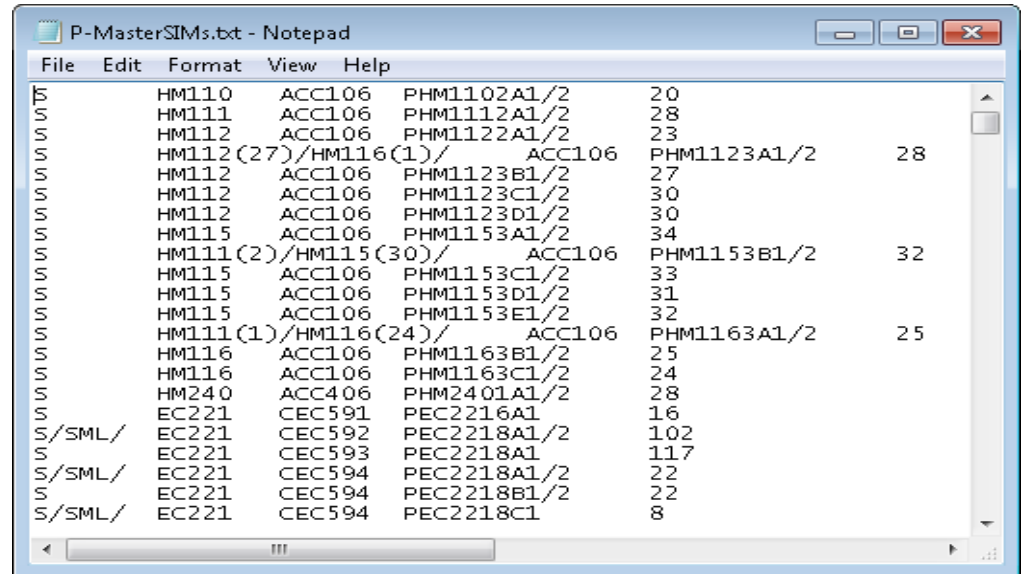

Figure 3: Enrolment Records

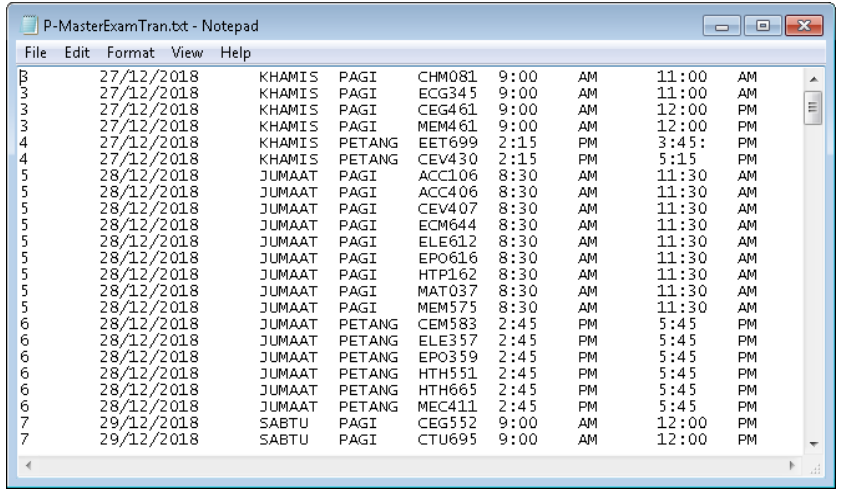

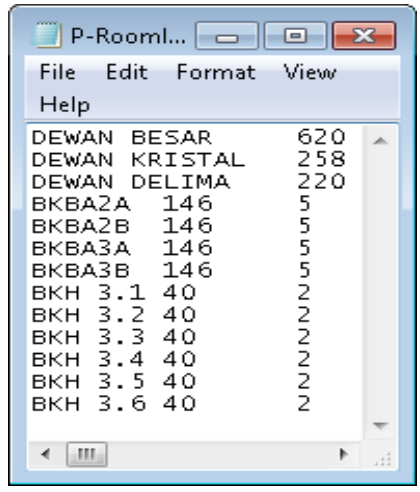


Figure 4: Examination Schedules Records

Figure 5: Examination Venue Lists

The enrolment and examination schedules records are integrated by using the subject code as the key index and produced the following results as shown in Figure 6 below.

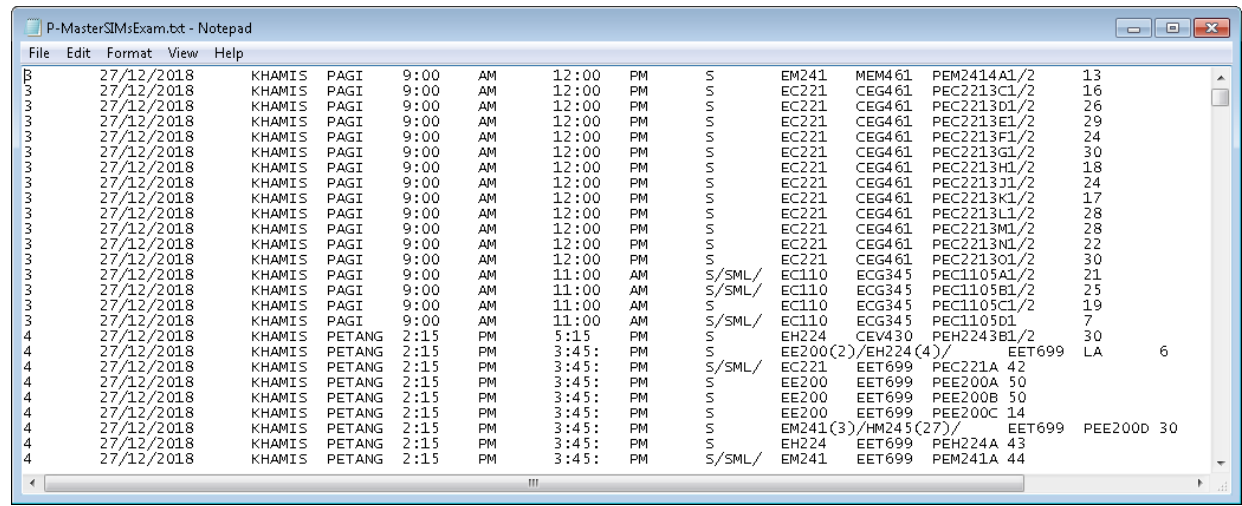

Figure 6: Integration Records of Enrolments and Examination Schedules

Using Simple Linear Sequential Techniques, the venues will be assigned to each of records (Figure 6) using the examination venue lists (Figure 5). An algorithm of Simple Linear Sequential Techniques has been designed and coded using JAVA programming language and executed under the Windows 10 operating system. Normal personal computer or laptop can be used to operate this application program. Simple Linear Sequential Techniques will consider elements of total enrolment for each examination session and will indicate if the capacity cannot meet the total number of enrolments and without violating the number of students exceeding the room capacity. The following figure shows the algorithm of the techniques.

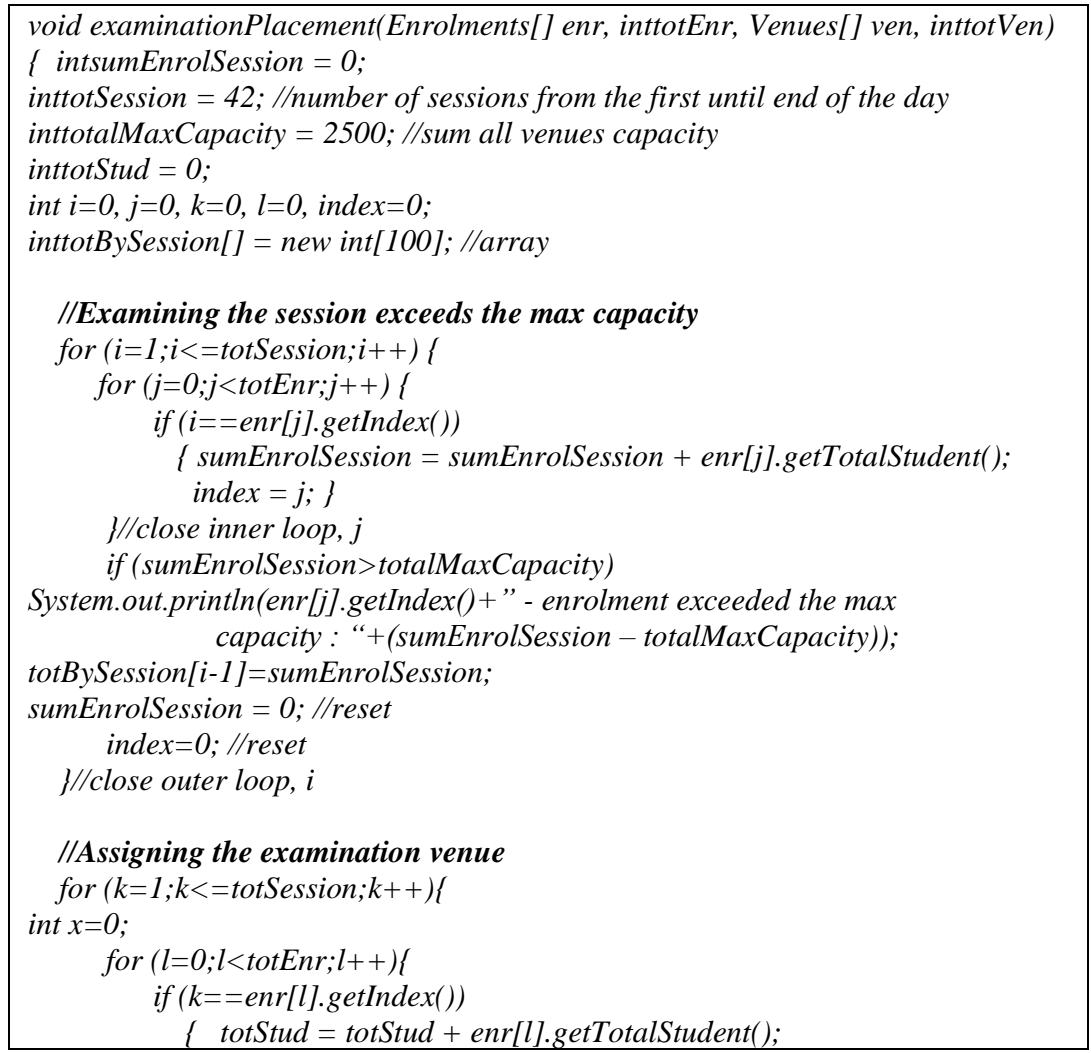




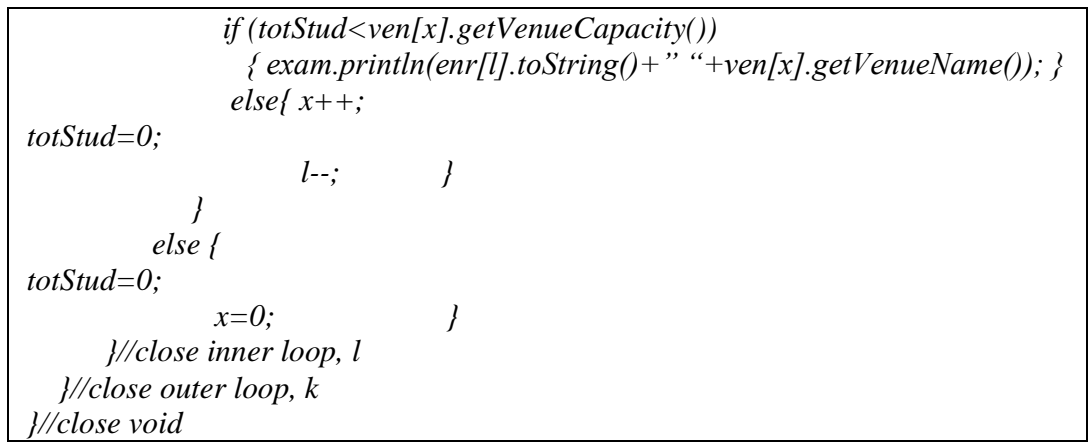

Figure 7: Algorithm of Simple Linear Sequential Techniques

\section{RESULT AND FINDINGS}

To test the effectiveness of the algorithm, the real data of examination records for December 2018 are used. The records are tested and Figure 8 shows the result.

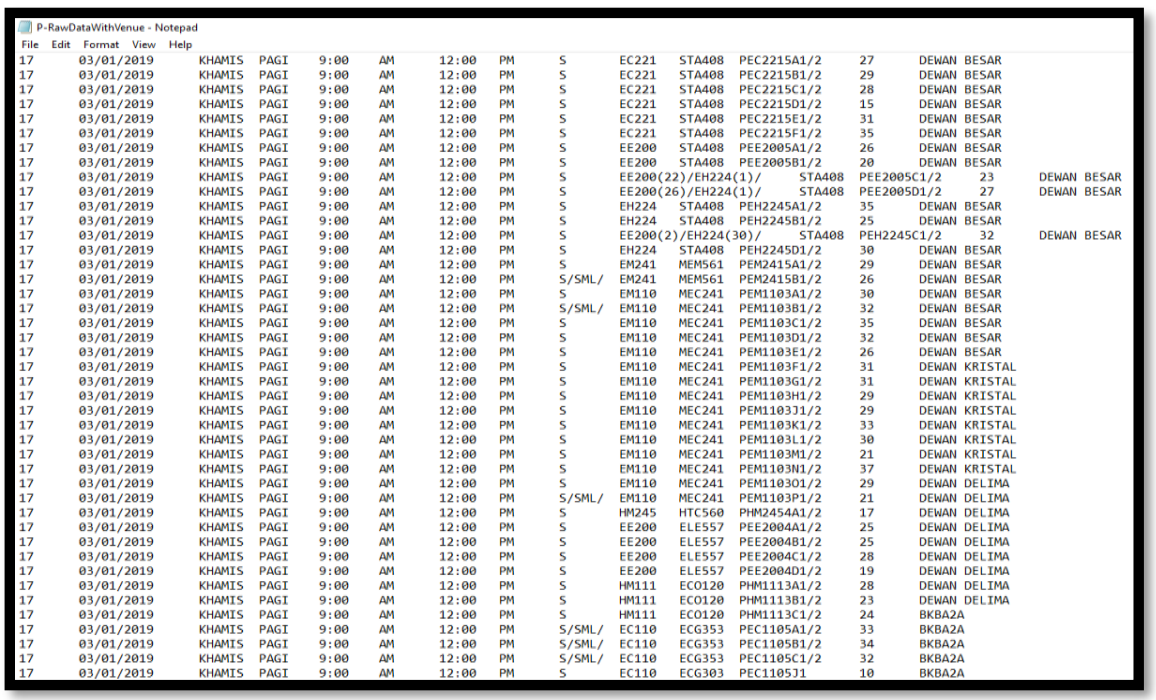

Figure 8: Examination Records with Venues

Based on the results, the algorithm is able to successfully assign appropriate venues to each of examination records without cases of overloaded issues or failures of assigning venues. The subjects with longer duration of examination hours are assigned at the front row, while the shorter hours are placed at the subsequent row as shown in the Figure 9.

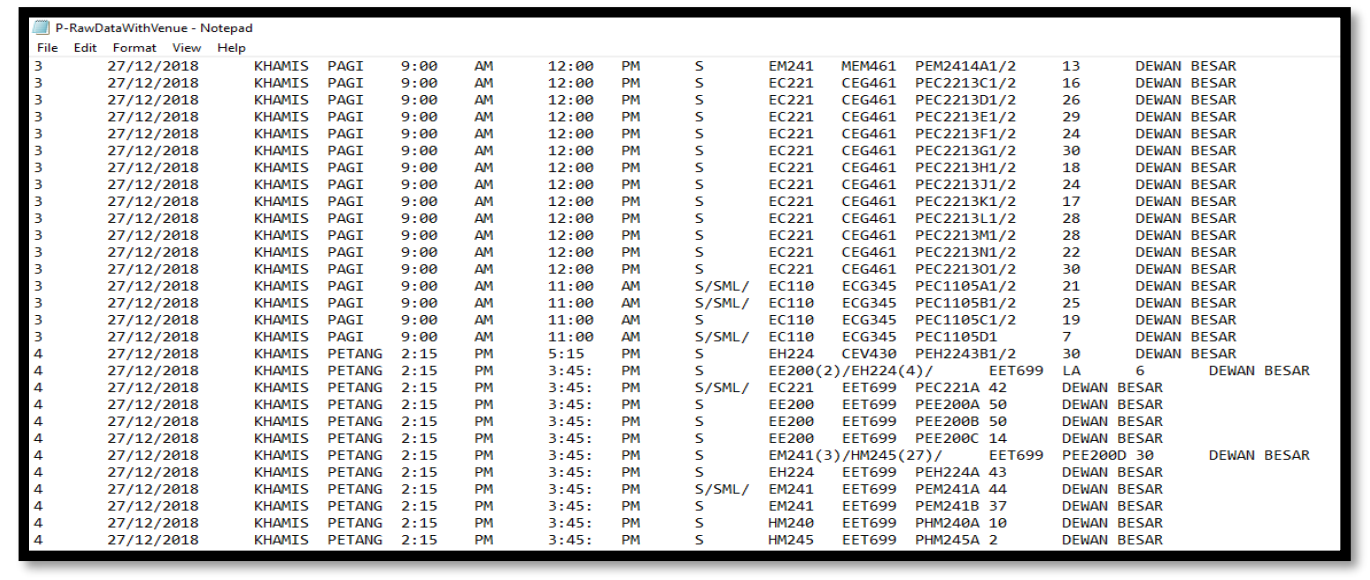


The reason for the subjects with different durations of examination hours are separated at different row in the examination hall is that whenever the subjects with shorter hours of examination durations are finished, the students can move and walk to the back of the hall without interrupting the students at the front row with longer hours to continue with their examination.

The results of examination records with venues have been analysed and minor alteration done manually to satisfy the soft constraints lists. The changes took less than 1 hour and percentage of changes is $9.2 \%$ from the original records, which are considered as acceptable.

The algorithm further tested with the previous semester examination records. Enhancement and improvising of the algorithm is the ultimate purpose when the test is conducted periodically and iteratively. The following table shows the list of tests using separate samples of examination records.

Table 3: List of Test

\begin{tabular}{|c|c|c|c|c|}
\hline $\begin{array}{l}\text { Examination } \\
\text { Session }\end{array}$ & $\begin{array}{l}\text { Total } \\
\text { Records }\end{array}$ & \multicolumn{1}{c}{$\begin{array}{l}\text { Successfully } \\
\text { Assigning Venues }\end{array}$} & $\begin{array}{l}\text { Total Records of } \\
\text { Manual Changes }\end{array}$ & $\begin{array}{c}\text { Percentage of } \\
\text { manual changes }\end{array}$ \\
\hline Dec 2018 & 2752 & $100 \%$ & 253 & $9.2 \%$ \\
\hline Jun 2018 & 2528 & $100 \%$ & 205 & $8.1 \%$ \\
\hline Dec 2017 & 2431 & $100 \%$ & 226 & $9.3 \%$ \\
\hline Jun 2017 & 2195 & $100 \%$ & 187 & $8.5 \%$ \\
\hline Dec 2016 & 2266 & $100 \%$ & 170 & $7.5 \%$ \\
\hline
\end{tabular}

Table 3 shows that the average of manual changes from 5 sessions of examination in percentage is $8.52 \%$. This percentage is acceptable (less than 10\%) and can be considered as a successful algorithm. Additionally, the algorithm has effectively assigned the examination venues to each record without fail. There are no issues of overloaded capacity problem and unassigned venues.

The algorithm is further tested at two other campuses such as UniversitiTeknologi MARA Perlis Branch (Arau Campus) and UniversitiTeknologi MARA Pulau Pinang Branch (Bertam Campus). The data have been collected from five examinations session using the same attributes and formats of examination records as in UniversitiTeknologi MARA Pulau Pinang Branch (PermatangPauh Campus). The following Table 4 shows the test result.

\begin{tabular}{|c|c|c|}
\hline $\begin{array}{l}\text { Table } \\
\text { Result } \\
\text { UiTM }\end{array}$ & $\begin{array}{l}\text { UiTM Perlis Branch } \\
\text { (Arau Campus) }\end{array}$ & $\begin{array}{l}\text { UiTMPulauPinang Branch } \\
\text { (Bertam Campus) }\end{array}$ \\
\hline
\end{tabular}




\begin{tabular}{|c|c|c|c|c|c|c|}
\hline & 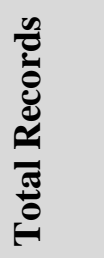 & 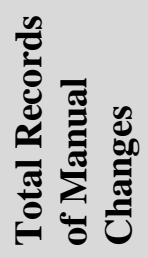 & 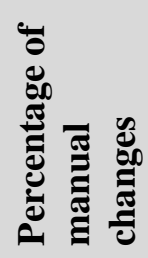 & 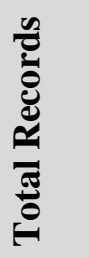 & 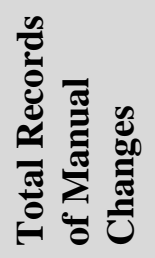 & 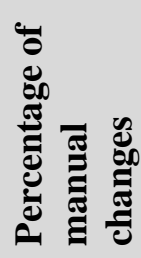 \\
\hline Dec 2018 & 3016 & 217 & $7.2 \%$ & 328 & 8 & $2.3 \%$ \\
\hline June 2018 & 3168 & 247 & $7.8 \%$ & 412 & 0 & $0.0 \%$ \\
\hline Dec 2017 & 3242 & 250 & $7.7 \%$ & 387 & 5 & $1.3 \%$ \\
\hline June 2017 & 3248 & 263 & $8.1 \%$ & 425 & 9 & $2.2 \%$ \\
\hline Dec 2016 & 3227 & 307 & $9.5 \%$ & 403 & 0 & $0.0 \%$ \\
\hline
\end{tabular}

The Table 4 shows that for UiTM Perlis Branch (Arau Campus), the average percentage of manual changes is still below than $10 \%$, while the result from UiTMPulau Pinang Branch (Bertam Campus) is better than UiTMPulau Pinang Branch (PermatangPauh Campus) which the result is less than $3 \%$. The test results for the three campuses of UiTM are significant.

The staffs of Examination Unit responded positively to the process of examination placement that can be done automatically and with minimal changes. Prior experience of manual preparation of examination placement using Microsoft Excel, took almost 5 to 6 hours (1 day) to be completed. Furthermore, this task will be prepared concurrently by three persons. With the new application program or tools using Simple Linear Sequential algorithm, the task can be completed within an hour and only a person is needed to handle the application.

\section{CONCLUSION AND FUTURE WORK}

In line with Bhardwaj\& Singh (2011), Examination Management Systems (EMS) is able to improve the efficiency and effectiveness of examination administration. The application allows decreasing in resources needed to accomplish the task. Several benefits from this automated placement application are identified, such as:-

- using this application, the number of Examination Unit staffs that are responsible to allocate students into examination's room can be reduced into one person only.

- this application enables the task to complete within less than an hour.

- and roughly the examination unit has reduced the duty of examination preparation amongst staffs during weekends. This has reduced a lot of the overtime cost amongst their staffs. Indirectly EMS improves the quality time with their family because there is no interruption of examination responsibility during weekends, hence reducing their stress.

Enhancement of EMS is an on-going process whenever there are suggestions or positive comments given by the users or Examination Unit staffs and as well as through benchmarking platforms by UiTM campuses, faculties and local or private universities. Thus, for the improvement of EMS, the Examination Unit will continuously support the operation of EMS and with continuously good rapport.

Furthermore, the application of examination placement or the algorithm needs further enhancement to consider other aspects of soft constraints such as:- 
- the flexibility of splitting different hours of examination duration in separate examination venues. For example, the two hours and three hours examination duration cannot be combined in the same examination venue.

- diverting the subject with special requirement to a specific examination venue. For example, the subject that requires the students answering question by using the computer, will be automatically assigned to the computer laboratory.

- not to assign more than 5 subjects code in the same examination venues. This is requested by the invigilators to avoid any negligence since there are facing difficulties in handling and managing multiple subject codes especially in the examination halls.

- assigning students into rooms based on the capacity of candidate per session. The algorithm should be able to assign students into the examination rooms based on the total students per session. The scenarios are if the volume of candidates for that session is small, then the algorithm needs to be able to match the small capacity of rooms as the first priority. On the other hand, if the total numbers of candidate for that session are large, then, the rooms that have large capacity should be the first priority.

- extending the examination placement application to table number system for sitting arrangement in the examination halls. The student will be arranged accordingly and systematically in the examination halls.

More soft constraints will be identified and if it is identical and appropriate, the existing algorithm will be reviewed and enhanced to produce a more comprehensive examination placement algorithm. Simple Linear Sequential Techniques is the beginning of the journey for the achievement of the project. In the future, we hope there are more innovative ideas can be represented to further improvises the algorithm to become more efficient and effective examination placement technique.

\section{REFERENCES}

Abdullah, S. (2006). Heuristic Approaches for University Timetabling Problems. 1-226.

Bhardwaj, M., \& Singh, A. J. (2011). Automated integrated university examination system. Himachal Pradesh University Journal, 1, 156-162.

Benko, A., Gyorgy, D. (2014), Theoretical and Practical Examination of Bin Packing and Scheduling Problem, Phd Thesis, Department of Mathematics, University of Pannonia.

Bloomfield, S.D., McSharry, M.M. (1979). Preferential Course Scheduling. 9(4), 24-31.

Burke, E., Jackson, K., Kingston, J., Weare, R.(1997). Automated Timetabling : The State of the Art. $1-8$.

Chand, A. (2002). A Heuristic Approach to Constraint Optimization in Timetabling. Journal of the Short Communication, 20, 64-67.

Hicks, B. J., Medland, A. J., Mullineux, G., "The representation and handling of constraints for the design, analysis and optimization of high speed machinery", Artificial Intelligence for Engineering Design, Analysis and Manufacture (AIEDAM), 20 (2006) 313-328.

Kenneth E. Kendall, Julie E. Kendall., Systems Analysis and Design, Pearson, 2014 
Othman J., AbdWahab N., Kadar R., Warris S.N. (2017), Assigning Examination Invigilator'sSchedule Problem: An Approach ofProgramming Techniques using SimpleSequential Assignment, Computing Research\& Innovation(CRINN), Vol. 2, 1-13.

Quality (2010). Quality Manual of UiTM Cawangan Pulau Pinang, I. 9001:2008. (n.d.). Quality Manual of UiTM Cawangan Pulau Pinang, ISO 9001:2008.

UiTM. (2016). Examination Procedures Manual, Academic Assessment Division of UiTM. Springer.

Wren, A. (1996). Scheduling, Timetabling and Rostering - A Special Relationship? , Practice and Theory of Automated Timetabling, Lecture Notes in Computer Science, Vol. 1153, 1996, pp. 46-75. 